Physical Activity and Nutrition I 2021;25(2):026-032

Received: 2021/06/08, Revised: 2021/06/29, Accepted: 2021/06/29, Published: 2021/06/30 @2021 Ji Young Kim et al.; Licence Physical Activity and Nutrition. This is an open access article distributed under the terms of the creative commons attribution license (https:/l creativecommons.org/licenses/by-nc/2.0/), which permits unrestricted use, distribution, and reproduction in any medium, provided the orginal work is properly cited.

${ }^{*}$ Corresponding author : Kiwon Lim

Laboratory of Exercise Nutrition, Department of Physical Education, Konkuk University 120, Neungdong-ro, Gwangjin-gu, Seoul 05029, Republic of Korea

Tel: +82-2-450-3827 / Fax: +82-452-6027

E-mail: exercise@konkuk.ac.kr

@2021 The Korean Society for Exercise Nutrition

[Purpose] This study aimed to analyze the prevalence of hypertension according to the body mass index (BMI) and relative handgrip strength (RHGS) among elderly individuals in Korea.

[Methods] We analyzed the data of 44,183 Korean elderly individuals over 65 years old (men: $n=15,798$, age $=73.31+5.04$ years, women: $n=28,385$, age $=$ $72.14 \pm 5.04$ years) obtained from the Korean National Fitness Assessment in 2019. All the participants were categorized into three groups according to the BMI and RHGS; additionally, one-way ANOVA and logistic regression analysis were performed.

[Results] Overweight (men: 1.16 odds ratio [OR] 1.06-1.26, 95\% confidence interval [Cl]; women: 1.15 OR, 1.07-1.23 95\% Cl) and obese (men: $1.54 \mathrm{OR}$, $1.42-1.66$ 95\% Cl; women: 1.44 OR, 1.36-1.53 95\% $\mathrm{Cl}$ ) elderly individuals showed a higher prevalence of hypertension than elderly individuals with normal weight, after controlling for age. In men, a lower RHGS was associated with a higher prevalence of hypertension after controlling for age (weak RHGS: 1.09 OR, 1.00-1.17 95\% Cl; middle RHGS: 1.21 OR, 1.12-1.31 $95 \% \mathrm{Cl}$ vs. strong RHGS)

[Conclusion] A higher BMI was associated with the prevalence of hypertension in the elderly Korean population. In addition, a lower RHGS was associated with the prevalence of hypertension in elderly Korean men.

[Key words] hypertension, obesity, body mass index, relative handgrip strength, elderly, Korean national fitness assessment

\section{Body mass index and relative handgrip strength are associated with the prevalence of hypertension in Korean elderly: Korean national fitness assessment in 2019}

\author{
Ji Young Kim ${ }^{1}$ / Hun-Young Park ${ }^{1,2}$ / Jisu Kim ${ }^{1,2}$ / Kiwon Lim ${ }^{1,2,3^{*}}$ \\ 1. Physical Activity and Performance Institute (PAPI), Konkuk University, Seoul, Republic of Korea \\ 2. Department of Sports Medicine and Science in Graduate School, Konkuk University, Seoul, Republic of \\ Korea \\ 3. Department of Physical Education, Konkuk University, Seoul, Republic of Korea
}

\section{INTRODUCTION}

The creation of an aging society is accelerating due to the developments in medicine, and an increase in chronic diseases, such as cardiovascular diseases, diabetes, and cancer is emerging as a serious social problem. The prevalence of these chronic diseases increases with age, and it was found that $89.5 \%$ of the elderly population aged 65 years and over suffered from at least one chronic disease in Korea ${ }^{1}$.

Hypertension is one of the most common chronic diseases of the cardiovascular system and is a major cause of diseases, such as coronary artery disease, stroke, and renal failure ${ }^{2,3}$. In Korea, approximately $30 \%$ of adults aged 30 years and older suffer from hypertension, indicating a high prevalence of chronic diseases ${ }^{4}$. The risk factors for hypertension include weight gain, unhealthy eating habits, excessive sodium intake, lack of physical activity, and excessive alcohol intake ${ }^{5}$. In particular, hypertension is closely related to weight gain, and a high obesity index, such as body mass index (BMI), waist circumference, and body fat percentage increases the prevalence of hypertension ${ }^{6-9}$.

Muscles play an important role in the energy metabolism of the body and are highly correlated with metabolic diseases, such as obesity, diabetes, and metabolic syndrome ${ }^{10-12}$. In addition, muscle strength is mainly used as a risk predictor of metabolic diseases because it reflects not only the muscle mass but also the level of physical activity ${ }^{13,14}$. Sarcopenia occurs due to the deterioration of muscle function, structure, and activity as aging progresses in the elderly, and muscles decrease by $\sim 8 \%$ for 10 years from the age of 40 years, and $\sim 15 \%$ for 10 years from the age of 70 years ${ }^{15}$. Sarcopenia and muscle weakness are expected to be closely associated with the high prevalence of hypertension in the elderly. According to a study that analyzed the correlation between BMI, muscle mass, and blood pressure (BP) in 121 elderly men with borderline hypertension in Korea, if the BMI was $>25 \mathrm{~kg} / \mathrm{m}^{2}$ or the muscle mass decreased, hypertension was likely to develop ${ }^{16}$. In addition, a study investigating the relationship between hand grip strength (HGS) and hypertension in adults and the elderly using large-scale data from the National Health and 
Nutrition Examination Survey showed that the prevalence of hypertension was lower when the HGS was high ${ }^{17,18}$.

HGS is mainly used as a simple, convenient, and economical tool to evaluate muscle strength; it is known that when measuring HGS in an upright posture, the force of the lower body and core muscles is reflected ${ }^{19}$. Since HGS is closely related to weight, it is recommended to use relative HGS (RHGS) obtained by dividing the grip strength by body weight ${ }^{20}$. Recent studies investigating the relationship between RHGS and chronic diseases, such as metabolic syndrome and diabetes, are being conducted continuous$1 y^{12,21,22}$.

Although previous studies investigated the effects of muscle strength and obesity indicators, such as BMI and waist circumference, on hypertension, they have only investigated individual correlations with each indicator. In addition, few studies have examined the relationship between BMI, RHGS, and hypertension in the elderly. Furthermore, for HGS, it would be difficult to draw a result completely excluding the effect of body weight, since most of the studies used absolute HGS rather than RHGS. Therefore, the purpose of this study was to analyze the association between the prevalence of hypertension, BMI, and RHGS among elderly individuals in Korea.

\section{METHODS}

\section{Participants}

The National Physical Fitness Survey-National Fitness 100 - is a sports welfare service that measures and evaluates physical fitness by scientific methods and provides exercise counseling and prescription ${ }^{23}$. In this study, participants aged 65 years or older who underwent physical fitness evaluations in the National Physical Fitness Survey conducted in 2019 were selected as participants. Of a total of 47,102 participants, the data from 44,183 participants (mean age $72.56 \pm 5.11$ years, 15,798 men and 28,385 women; Table 1) were used for analysis, (the remaining 2,919 participants did not have the data of body composition variables such as height and weight, BP or HGS data, or had excessively high or low variable values judged to be recording errors, and were therefore, excluded from the study).

\section{Measurements}

Body composition

The height was measured in the standing posture with bare feet on a stadiometer (Seca 213, Seca, Germany), and recorded in units of $0.1 \mathrm{~cm}$. The weight and percent body fat were assessed using InBody (InBody 720, Biospace, Korea) and BMI was defined as weight $/ \mathrm{height}^{2}\left(\mathrm{~kg} / \mathrm{m}^{2}\right)$.

\section{Blood pressure}

The systolic blood pressure (SBP) and diastolic blood pressure (DBP) were assessed using a validated automated sphygmomanometer (HEM-9000AI, Omron, Japan) after the participants sat quietly for $15 \mathrm{~min}$.

\section{Relative hand grip strength}

The HGS was measured using a hand dynamometer (GRIP-D 5101, Takei, Japan) in a standing position with both feet placed at shoulder-width. The hand dynamometer was made to fit the second knuckle of each participant's finger and pulled for 2-3 s according to the certified staff's signal. It was measured two times from left to right and alternately recorded the highest value to a $0.1 \mathrm{~kg}$ unit. The hands were divided into a dominant hand (mainly used hands) and a non-dominant hand. In this study, the RHGS was calculated by dividing the HGS by body weight.

\section{Assessment of hypertension}

In this study, hypertension was defined as an SBP $>140$ $\mathrm{mmHg}$ or DBP $>90 \mathrm{mmHg}$ according to the 2019 criteria of the Korean Society of Hypertension ${ }^{4}$.

\section{Statistical analysis}

The data were statistically analyzed using SPSS software (version 23.0; Statistical Package for the Social Science). The body composition, BP, and dominant HGS were compared using an independent $t$-test according to the sex. Since there were statistically significant differences in the body composition, BP, and dominant HGS between men and women, the analysis was conducted separately by sex. The BMI group was classified into normal weight $\left(<23.0 \mathrm{~kg} / \mathrm{m}^{2}\right)$, overweight $\left(23.0-24.9 \mathrm{~kg} / \mathrm{m}^{2}\right)$, and obese $\left(>25.0 \mathrm{~kg} / \mathrm{m}^{2}\right)$ according to the BMI. In addition, the RHGS group was classified as strong, middle, and weak according to the tertiles of RHGS in men ( $\leq 43.1 \%$ vs. $43.11-50.97 \%$ vs. $\geq 50.98 \%)$

Table 1. Characteristics of participants $(n=44,183)$.

\begin{tabular}{|c|c|c|c|}
\hline Variables & Men $(n=15,798)$ & Women $(n=28,385)$ & $p$-value \\
\hline Age (yr) & $73.31 \pm 5.04$ & $72.14 \pm 5.10$ & $<.001$ \\
\hline Height (cm) & $165.09 \pm 5.73$ & $152.66 \pm 5.33$ & $<.001$ \\
\hline Weight (kg) & $66.59 \pm 8.66$ & $57.66 \pm 7.83$ & $<.001$ \\
\hline BMI $\left(\mathrm{kg} / \mathrm{m}^{2}\right)$ & $24.41 \pm 2.76$ & $24.73 \pm 3.07$ & $<.001$ \\
\hline Percent body fat (\%) & $26.51 \pm 6.24$ & $35.11 \pm 6.27$ & $<.001$ \\
\hline $\mathrm{SBP}(\mathrm{mmHg})$ & $135.51 \pm 15.78$ & $131.59 \pm 15.05$ & $<.001$ \\
\hline $\mathrm{DBP}(\mathrm{mmHg})$ & $75.59 \pm 10.62$ & $74.24 \pm 10.12$ & $<.001$ \\
\hline Dominant HGS (kg) & $30.99 \pm 6.24$ & $19.94 \pm 4.63$ & $<.001$ \\
\hline RHGS (\%) & $46.92 \pm 9.47$ & $34.97 \pm 8.44$ & $<.001$ \\
\hline
\end{tabular}

Values are expressed as mean $\pm \mathrm{SD}$.

BMI, body mass index; SBP, systolic blood pressure; DBP, diastolic blood pressure; HGS, hand grip strength; RHGS, relative hand grip strength $p$-value $<.05$. 
and women ( $\leq 31.55 \%$ vs. $31.56-38.65 \%$ vs. $\geq 38.66 \%$ ), respectively. The comparisons of age, height, weight, BMI, body fat percentage, SBP, DBP, and RHGS between weight groups were analyzed with a one-way analysis of variance (ANOVA) and the post hoc Scheffe test. In addition, the odds ratios (ORs) and 95\% confidence intervals (CIs) for the prevalence of hypertension were calculated using a standard logistic regression model according to the BMI and RHGS adjusted for age. The statistical significance was set at $\mathrm{p}<$ 0.05 .

\section{RESULTS}

Comparisons in body composition, BP, and HGS by BMI group

There were statistically significant differences in the body composition, BP, dominant HGS, and RHGS in both sexes according to the BMI group (Table 2).

In men, the overweight and obese groups had significantly lower age $(p<.001)$ and RHGS $(p<.001)$, and higher body weight $(p<.001)$, body fat percentage $(p<.001)$, SBP $(p<.001)$, DBP $(p<.001)$, and dominant HGS $(p<.001)$ compared to the normal weight group, and the obese group had a lower height compared to the normal weight group ( $p$ $=.007)$. In addition, the obese group had significantly higher body weight $(p<.001)$, body fat percentage $(p<.001)$, SBP $(p<.001)$, DBP $(p<.001)$, and dominant HGS $(p<.001)$ and had lower height $(p=.001)$ and RHGS $(p<.001)$ than the overweight group.

In women, the overweight and obese groups were observed to have a significantly higher body weight $(p<.001)$, body fat percentage $(p<.001)$, SBP $(p<.001)$, DBP $(p<$ $.001)$, and dominant HGS $(p<.001)$ and lower height $(p<$ $.001)$ and RHGS $(p<.001)$ compared to the normal weight group. The obese group had a higher age than the normal-weight group $(p<.001)$. In addition, the obese group had a significantly higher age $(p<.001)$, body weight $(p<$ $.001)$, body fat percentage $(p<.001), \operatorname{SBP}(p<.001)$, DBP $(p<.001)$, and lower height $(p=.001)$, dominant HGS $(p<$ $.001)$, and RHGS $(p<.001)$ than the overweight group.

\section{Relationship between BMI and the prevalence of hypertension}

In the relationship between BMI and hypertension, the odds of having hypertension were significantly higher in the overweight and obese groups than in the normal weight group in both sexes (Table 3 ).

Table 2. Comparisons of body composition, blood pressure, and HGS according to the tertiles of BMI $(n=44,183)$.

\begin{tabular}{|c|c|c|c|c|c|c|}
\hline \multirow[b]{2}{*}{ Variables } & \multicolumn{3}{|c|}{ Men $(n=15,798)$} & \multicolumn{3}{|c|}{ Women $(n=28,385)$} \\
\hline & $\begin{array}{l}\text { Normal weight } \\
\qquad(n=4,663)\end{array}$ & $\begin{array}{l}\text { Overweight } \\
(n=4,580)\end{array}$ & $\begin{array}{c}\text { Obese } \\
(n=6,555)\end{array}$ & $\begin{array}{l}\text { Normal weight } \\
\qquad(\mathrm{n}=8,129)\end{array}$ & $\begin{array}{l}\text { Overweight } \\
\text { (n=7,722) }\end{array}$ & $\begin{array}{c}\text { Obese } \\
(n=12,534)\end{array}$ \\
\hline $\mathrm{BMI}\left(\mathrm{kg} / \mathrm{m}^{2}\right)$ & $21.25 \pm 1.40$ & $23.96 \pm 0.57^{*}$ & $26.98 \pm 1.71^{\star \#}$ & $21.28 \pm 1.36$ & $23.98 \pm 0.57^{*}$ & $27.44 \pm 2.13^{\star \#}$ \\
\hline Age (yr) & $73.74 \pm 5.12$ & $73.11 \pm 5.03^{*}$ & $73.15 \pm 4.97^{*}$ & $71.92 \pm 5.15$ & $72.01 \pm 5.08$ & $72.36 \pm 5.07^{\star \#}$ \\
\hline Height (cm) & $165.22 \pm 5.71$ & $165.28 \pm 5.69$ & $164.87 \pm 5.78^{\star \#}$ & $153.33 \pm 5.31$ & $152.87 \pm 5.32^{*}$ & $152.10 \pm 5.30^{* \#}$ \\
\hline Weight (kg) & $58.08 \pm 5.53$ & $65.52 \pm 4.72^{*}$ & $73.40 \pm 6.69^{\star \#}$ & $50.08 \pm 4.67$ & $56.11 \pm 4.09^{*}$ & $63.54 \pm 6.41^{\text {*\# }}$ \\
\hline Percent body fat (\%) & $21.91 \pm 5.35$ & $25.76 \pm 4.85^{*}$ & $30.31 \pm 5.21^{\star \#}$ & $29.65 \pm 5.30$ & $34.28 \pm 4.28^{*}$ & $39.16 \pm 4.84^{\star \#}$ \\
\hline $\mathrm{SBP}(\mathrm{mmHg})$ & $133.16 \pm 16.76$ & $135.15 \pm 15.36^{*}$ & $137.44 \pm 15.10^{\star \#}$ & $129.36 \pm 15.45$ & $131.25 \pm 15.12^{*}$ & $133.23 \pm 14.53^{* \#}$ \\
\hline $\mathrm{DBP}(\mathrm{mmHg})$ & $74.32 \pm 10.61$ & $75.31 \pm 10.39^{*}$ & $76.69 \pm 10.66^{\star \#}$ & $73.20 \pm 10.43$ & $74.14 \pm 9.92^{*}$ & $74.97 \pm 10.03^{* \#}$ \\
\hline Dominant HGS (kg) & $29.70 \pm 6.01$ & $31.23 \pm 6.18^{*}$ & $31.74 \pm 6.29 * \#$ & $19.61 \pm 4.43$ & $20.11 \pm 4.59^{*}$ & $20.04 \pm 4.76^{*}$ \\
\hline RHGS (\%) & $51.19 \pm 9.52$ & $47.67 \pm 8.91^{*}$ & $43.36 \pm 8.38^{\star \#}$ & $39.23 \pm 8.53$ & $35.82 \pm 7.65^{*}$ & $31.68 \pm 7.43^{\star \#}$ \\
\hline
\end{tabular}

Values are expressed as mean \pm SD.

BMI, body mass index; SBP, systolic blood pressure; DBP, diastolic blood pressure; HGS, hand grip strength; RHGS, relative hand grip strength ${ }^{*} p$-value $<.05$ vs. normal weight group, ${ }^{\#} p<.05$ vs. overweight group.

Table 3. Odds ratio and $95 \% \mathrm{Cl}$ for hypertension according to the tertiles of $\mathrm{BMI}(\mathrm{n}=44,183)$.

\begin{tabular}{|c|c|c|c|c|c|}
\hline & Tertiles & Crude & $p$-value & Model 1 & $p$-value \\
\hline \multirow{3}{*}{$\begin{array}{c}\text { Men } \\
(n=15,798)\end{array}$} & $\begin{array}{l}\text { Normal weight } \\
\qquad(n=4,663)\end{array}$ & 1 & - & 1 & - \\
\hline & $\begin{array}{l}\text { Overweight } \\
(n=4,580)\end{array}$ & $1.15(1.06-1.25)$ & .001 & $1.16(1.06-1.26)$ & .001 \\
\hline & $\begin{array}{c}\text { Obese } \\
(n=6,555)\end{array}$ & $1.53(1.42-1.65)$ & $<.001$ & $1.54(1.42-1.66)$ & $<.001$ \\
\hline \multirow{3}{*}{$\begin{array}{c}\text { Women } \\
(n=28,385)\end{array}$} & $\begin{array}{l}\text { Normal weight } \\
\quad(n=8,129)\end{array}$ & 1 & - & 1 & - \\
\hline & $\begin{array}{l}\text { Overweight } \\
(\mathrm{n}=7,722)\end{array}$ & $1.15(1.07-1.23)$ & $<.001$ & $1.15(1.07-1.23)$ & $<.001$ \\
\hline & $\begin{array}{c}\text { Obese } \\
(n=12,534)\end{array}$ & $1.46(1.37-1.55)$ & $<.001$ & $1.44(1.36-1.53)$ & $<.001$ \\
\hline
\end{tabular}

$\mathrm{Cl}=$ confidence interval, $\mathrm{BMI}=$ Body mass index.

Tertiles of $\mathrm{BMI}=$ normal weight $\left(<23.0 \mathrm{~kg} / \mathrm{m}^{2}\right)$ vs. overweight $\left(23.0 \sim 24.9 \mathrm{~kg} / \mathrm{m}^{2}\right)$ vs. obese $\left(>25.0 \mathrm{~kg} / \mathrm{m}^{2}\right)$

Model 1 = adjusted for age.

$p$-value $<.05$. 
In men, the overweight and obese groups had 1.15 times (95\% Confidence interval; $\mathrm{CI}=1.06-1.25)$ and 1.53 times $(95 \% \mathrm{CI}=1.42-1.65)$ higher odds of having hypertension, respectively, compared to the normal weight group. Even after controlling for age, the overweight group had 1.16 times $(95 \% \mathrm{CI}=1.06-1.26)$ and the obese group had 1.54 times $(95 \% \mathrm{CI}=1.42-1.66)$ higher odds of having hypertension, respectively, compared to the normal weight group.

In women, the overweight and obese groups had 1.15 times $(95 \% \mathrm{CI}=1.07-1.23)$ and 1.46 times $(95 \% \mathrm{CI}=$ 1.37-1.55) higher odds of having hypertension, respectively, compared to the normal weight group. Even after controlling for age, the overweight group had 1.15 times (95\% $\mathrm{CI}=1.07-1.23)$ and the obese group had 1.44 times $(95 \%$ $\mathrm{CI}=1.36-1.53$ ) higher odds of having hypertension, respectively, compared to the normal weight group.

\section{Comparisons in body composition, BP, and HGS by RHGS group}

There were statistically significant differences in the body composition, BP, and dominant HGS in both sexes according to the RHGS group (Table 4).

In men, the 2nd (middle) and 3rd (weak) tertiles of the RHGS had significantly higher age $(p<.001)$, body weight $(p<.001)$, BMI $(p<.001)$, body fat percentage $(p<.001)$, and SBP $(p<.001)$, and a lower dominant HGS $(p<.001)$ compared to the 1st (strong) tertile of the RHGS. In addition, the 3rd (weak) tertile of the RHGS had a higher age ( $p$ $<.001)$, body weight $(p<.001)$, BMI $(p<.001)$, and body fat percentage $(p<.001)$, and lower height $(p=.001)$, SBP $(p=.027)$, DBP $(p=.015)$, and HGS $(p<.001)$ compared to the 2nd (middle) tertile of the RHGS

In women, the 2 nd (middle) and 3 rd (weak) tertiles of the RHGS had a significantly higher age $(p<.001)$, body weight $(p<.001)$, BMI $(p<.001)$, and body fat percentage $(p<.001)$, and a lower height $(p<.001)$ and dominant HGS $(p<.001)$ compared to the 1st (strong) tertile of the RHGS. Moreover, the 3rd (weak) tertile of the RHGS had higher age $(p<.001)$, body weight $(p<.001)$, BMI $(p<.001)$, and body fat percentage $(p<.001)$, and lower height $(p=.001)$, $\operatorname{SBP}(p=.027), \operatorname{DBP}(p=.015)$, and HGS $(p<.001)$ com- pared to the 2nd (middle) tertile of the RHGS.

\section{Relationship between RHGS and the prevalence of} hypertension

In the relationship between RHGS and hypertension, the odds of having hypertension were significantly higher in the 2nd (middle) and 3rd (weak) tertiles than in the 1st (strong) tertile of the RHGS in both sexes (Table 5).

In men, the 2nd (middle) and 3rd (weak) tertiles of the RHGS had 1.22 times $(95 \% \mathrm{CI}=1.13-1.32)$ and 1.10 times $(95 \% \mathrm{CI}=1.02-1.18)$ higher odds of having hypertension, respectively, compared to the 1 st (strong) tertile of the RHGS. Even after controlling for age, the 2nd (middle) tertile of the RHGS had 1.21 times (95\% CI 1.13-1.31) and the 3rd (weak) tertile of the RHGS had 1.09 times $(95 \%$ CI $=1.00-1.17)$ higher odds of having hypertension compared to the 1st (strong) tertile of the RHGS.

In women, the 2nd (middle) and 3rd (weak) tertiles of the RHGS had 1.08 times $(95 \% \mathrm{CI}=1.01-1.15)$ and 1.09 times (95\% CI $=1.03-1.16)$ higher odds of having hypertension, respectively, compared to the 1 st (strong) tertile of the RHGS. However, there were statistically significant differences between the groups after controlling for age.

\section{DISCUSSION}

This study was conducted to investigate the relationship between the prevalence of hypertension, BMI, and RHGS in the elderly using data from the 2019 National Physical Fitness Survey. The results showed that elderly men and women with high BMI, and elderly men with weak RHGS were more likely to have hypertension.

The results of this study suggest that weight management is important for the prevention and management of hypertension in the elderly. BMI is the most commonly used index in the field of clinical practice and can be calculated easily using weight and height ${ }^{16}$. Since it has also been used in several previous studies, it has the advantage of being easy to compare among countries by age group. Although BMI has a limitation in that it may not clearly reflect the

Table 4. Comparisons of body composition, blood pressure, and HGS according to the tertiles of RHGS ( $n=44,182)$.

\begin{tabular}{|c|c|c|c|c|c|c|}
\hline \multirow[b]{2}{*}{ Variables } & \multicolumn{3}{|c|}{ Men $(n=15,798)$} & \multicolumn{3}{|c|}{ Women $(n=28,384)$} \\
\hline & $\begin{array}{l}\text { Strong RHGS } \\
(n=5,360)\end{array}$ & $\begin{array}{l}\text { Middle RHGS } \\
(n=5,210)\end{array}$ & $\begin{array}{l}\text { Weak RHGS } \\
(n=5,228)\end{array}$ & $\begin{array}{l}\text { Strong RHGS } \\
(n=9,459)\end{array}$ & $\begin{array}{l}\text { Middle RHGS } \\
\quad(n=9,533)\end{array}$ & $\begin{array}{l}\text { Weak RHGS } \\
(n=9,392)\end{array}$ \\
\hline RHGS (\%) & $56.98 \pm 4.62$ & $46.97 \pm 2.25^{*}$ & $36.56 \pm 5.73^{\star \#}$ & $44.00 \pm 4.52$ & $35.11 \pm 2.02^{*}$ & $25.73 \pm 4.82^{\star \#}$ \\
\hline Age (yr) & $72.08 \pm 4.73$ & $73.22 \pm 4.96^{*}$ & $74.66 \pm 5.09^{* \#}$ & $70.84 \pm 4.54$ & $71.78 \pm 4.93^{*}$ & $73.81 \pm 5.33^{\star \#}$ \\
\hline Height $(\mathrm{cm})$ & $165.21 \pm 5.51$ & $165.40 \pm 5.59$ & $164.66 \pm 6.07^{\star \#}$ & $153.13 \pm 5.30$ & $152.93 \pm 5.24^{*}$ & $151.92 \pm 5.37^{\star \#}$ \\
\hline Weight (kg) & $63.04 \pm 7.54$ & $67.35 \pm 8.00^{*}$ & $69.48 \pm 9.10^{\star \#}$ & $54.32 \pm 6.68$ & $58.18 \pm 7.05^{*}$ & $60.50 \pm 8.39^{* \#}$ \\
\hline $\mathrm{BMI}\left(\mathrm{kg} / \mathrm{m}^{2}\right)$ & $23.08 \pm 2.39$ & $24.60 \pm 2.48^{*}$ & $25.59 \pm 2.80^{\star \#}$ & $23.15 \pm 2.48$ & $24.87 \pm 2.67^{*}$ & $26.19 \pm 3.23^{\star \#}$ \\
\hline Percent body fat (\%) & $23.15 \pm 5.46$ & $26.75 \pm 5.46^{*}$ & $29.72 \pm 5.95^{\star \#}$ & $31.81 \pm 5.75$ & $35.59 \pm 5.38^{*}$ & $37.94 \pm 6.09^{\star \#}$ \\
\hline $\mathrm{SBP}(\mathrm{mmHg})$ & $134.47 \pm 16.06$ & $136.46 \pm 15.40^{*}$ & $135.64 \pm 15.81^{* \#}$ & $130.95 \pm 15.06$ & $131.78 \pm 15.04^{*}$ & $132.03 \pm 15.03^{*}$ \\
\hline $\mathrm{DBP}(\mathrm{mmHg})$ & $75.88 \pm 10.59$ & $75.74 \pm 10.53$ & $75.14 \pm 10.71^{\text {*\# }}$ & $74.46 \pm 9.88$ & $74.36 \pm 10.11$ & $73.89 \pm 10.35^{\star \#}$ \\
\hline Dominant HGS (kg) & $35.82 \pm 4.40$ & $31.62 \pm 3.93^{*}$ & $25.40 \pm 5.18^{\star \#}$ & $23.82 \pm 3.24$ & $20.41 \pm 2.60^{*}$ & $15.55 \pm 3.56^{\star \#}$ \\
\hline
\end{tabular}

Values are expressed as mean \pm SD.

RHGS, relative hand grip strength; BMI, body mass index; SBP, systolic blood pressure; DBP, diastolic blood pressure; HGS, hand grip strength ${ }^{*} p$-value $<.05$ vs. strong RHGS group, ${ }^{\#} p<.05$, vs. middle RHGS group. 
Table 5. Odds ratio and $95 \% \mathrm{Cl}$ for hypertension according to the tertiles of RHGS $(n=44,182)$.

\begin{tabular}{|c|c|c|c|c|c|}
\hline & Tertiles & Crude & $p$-value & Model 1 & $p$-value \\
\hline \multirow{3}{*}{$\begin{array}{c}\text { Men } \\
(n=15,798)\end{array}$} & $\begin{array}{l}\text { Strong RHGS } \\
(n=5,360)\end{array}$ & 1 & - & 1 & - \\
\hline & $\begin{array}{l}\text { Middle RHGS } \\
(n=5,210)\end{array}$ & $1.22(1.13-1.32)$ & $<.001$ & $1.21(1.12-1.31)$ & $<.001$ \\
\hline & $\begin{array}{l}\text { Weak RHGS } \\
(n=5,228)\end{array}$ & $1.10(1.06-1.18)$ & .019 & 1.09 (1.00-1.17) & .042 \\
\hline \multirow{3}{*}{$\begin{array}{c}\text { Women } \\
(n=28,384)\end{array}$} & $\begin{array}{l}\text { Strong RHGS } \\
(n=9,459)\end{array}$ & 1 & - & 1 & - \\
\hline & $\begin{array}{l}\text { Middle RHGS } \\
\qquad(n=9,533)\end{array}$ & $1.08(1.01-1.15)$ & .016 & $1.05(0.98-1.11)$ & .159 \\
\hline & $\begin{array}{c}\text { Weak RHGS } \\
(n=9,392)\end{array}$ & 1.09 (1.03-1.16) & .005 & $0.99(0.93-1.06)$ & .159 \\
\hline
\end{tabular}

$\mathrm{Cl}=$ confidence interval, $\mathrm{RHGS}=$ relative hand grip strength .

Tertiles of RHGS for men = strong RHGS ( $\leq 43.1 \%)$ vs. middle RHGS $(43.11 \sim 50.97 \%)$ vs. weak RHGS $(\geq 50.98 \%)$, for women = strong RHGS $(\leq 31.55 \%)$ vs. middle RHGS $(31.56 \%-38.65 \%)$ vs. weak RHGS $(\geq 38.0 \%)$

Model 1 = adjusted for age.

$p$-value $<.05$.

body fat mass component, it has a high correlation with the percentage of muscle mass ${ }^{24}$, and is often used as an indicator of obesity in clinical practice due to its high level of association with the risk of metabolic diseases. The results of the study showed that the elderly who were overweight or obese had a higher age, height, weight, BMI, body fat percentage, SBP, DBP, and HGS compared to the elderly with normal-weight. According to a previous study on the differences and correlation of body composition and functional fitness in the elderly population, the body composition and functional fitness of the elderly were weakened with increasing age, and their SBP and DBP increased with increasing BMI and waist circumference ${ }^{25}$. In addition, a previous study that analyzed the risk factors for hypertension in the elderly aged 65 years or older reported that the prevalence of hypertension was found to increase when the BMI was high or diabetes was diagnosed ${ }^{26}$. Indeed, hypertension is an aging-related chronic disease; thus, the management of risk factors - weight and muscle strength - is important to prevent and manage hypertension in the elderly.

In particular, according to the results of this study, the absolute HGS was high in the overweight and obese groups; however, the RHGS was low, suggesting that the absolute HGS can be greatly affected by body weight. RHGS is a value obtained by dividing the HGS by the body weight. Even if the HGS value is similar, the RHGS is estimated to be low if the body weight is high. Therefore, RHGS should be used as a predictor of hypertension rather than absolute HGS.

In this study, the group with weak RHGS was more likely to have hypertension than the group with strong RHGS in men, while there was no significant difference in women. The analysis of the percentage of hypertension according to the RHGS groups revealed that $41.4 \%$ of the strong RHGS group, $46.3 \%$ of the middle RHGS group, and $43.7 \%$ of the weak RHGS group were found to have hypertension. In women, $31.8 \%$ of the strong RHGS group, $33.4 \%$ of the middle RHGS group, and $33.7 \%$ of the weak RHGS group were found to have hypertension. In both groups, the weak
RHGS group was more likely to have hypertension compared to the other two RHGS groups; however, in the case of women, the difference in the percentage of patients with hypertension between the RHGS groups was rather small, and no statistically significant results were obtained.

According to previous studies, HGS has been a factor in predicting hypertension because it reflects exercise participation as well as muscle strength. Lee ${ }^{17}$ reported that the average number of days of high-intensity exercise, strength exercise, and flexibility exercise in participants with high HGS was more than 3 days. Furthermore, HGS exercise has a positive effect on BP reduction. According to a literature review on HGS exercise, it was reported that grip strength exercise intervention was effective in lowering SBP up to 13 $\mathrm{mmHg}$ or more and DBP up to $8 \mathrm{mmHg}$ or more ${ }^{27}$.

According to statistics of the elderly provided by Statistics Korea, $15.7 \%$ of the population aged 65 years and above in Korea in 2020 is expected to become a super-aged society of $20.3 \%$ by $2025^{28}$. Improving the health of the elderly is considered a very important issue for improving the quality of life of individuals and reducing social costs, including medical expenses. Once hypertension occurs, continuous management is required, which is a major cause of increased medical expenses for the elderly and increased burden on their dependents. Because hypertension is a cause of cardiovascular disease that can lead to serious sequelae or death, prevention and management of hypertension are essential for the elderly. Therefore, longitudinal studies to clearly identify and follow up risk factors for hypertension should be conducted to prevent hypertension in the elderly and to maintain a national management system to prevent secondary diseases.

This study has several limitations. First, there may be selection bias as the elderly individuals selected as participants in this study were limited to those whose body composition and physical strength were measured in 2019. In addition, we could not determine whether the participants were taking antihypertensive drugs. As BP was lowered when taking antihypertensive drugs, the measured value would be lower 
than the criteria for determining hypertension in this study; therefore, it may not be classified as hypertension. Thus, further studies should investigate whether antihypertensive drugs are being taken or not. Finally, demographic characteristics, such as education, income level, and occupation were not sufficiently reflected in this study. Since chronic diseases, such as hypertension are closely related to these socioeconomic factors, a study to analyze the risk factors for hypertension according to factors, such as education level, income level, and occupation should be conducted.

In conclusion, this study confirmed that weight management is necessary for the prevention and management of hypertension in the elderly. Furthermore, RHGS, which reflects weight, was also identified as a predictor of hypertension in elderly men.

\section{ACKNOWLEDGEMENTS}

This work was supported by the Ministry of Education of the Republic of Korea and the National Research Foundation of Korea (NRF-2019S1A5B8099542).

\section{REFERENCES}

1. Korea Institute for Health and Social Affairs. 2017 Survey on the Status of the Elderly; 2017.

2. Forouzanfar MH, Liu P, Roth GA, Ng M, Biryukov S, Marczak L, Alexander L, Estep K, Hassen Abate K, Akinyemiju TF, Ali R, Alvis-Guzman N, Azzopardi P, Banerjee A, Bärnighausen T, Basu A, Bekele T, Bennett DA, Biadgilign S, Catalá-López F, Feigin VL, Fernandes JC, Fischer F, Gebru AA, Gona P, Gupta R, Hankey GJ, Jonas JB, Judd SE, Khang YH, Khosravi A, Kim YJ, Kimokoti RW, Kokubo Y, Kolte D, Lopez A, Lotufo PA, Malekzadeh R, Melaku YA, Mensah GA, Misganaw A, Mokdad AH, Moran AE, Nawaz $\mathrm{H}$, Neal B, Ngalesoni FN, Ohkubo T, Pourmalek F, Rafay A, Rai RK, Rojas-Rueda D, Sampson UK, Santos IS, Sawhney M, Schutte AE, Sepanlou SG, Shifa GT, Shiue I, Tedla BA, Thrift AG, Tonelli M, Truelsen T, Tsilimparis N, Ukwaja KN, Uthman OA, Vasankari T, Venketasubramanian N, Vlassov VV, Vos T, Westerman R, Yan LL, Yano Y, Yonemoto N, Zaki ME, Murray CJ. Global burden of hypertension and systolic blood pressure of at least 110 to $115 \mathrm{~mm} \mathrm{Hg}, 1990-2015$. Jama. 2017;317:165-82.

3. Gakidou E, Afshin A, Abajobir AA, Abate KH, Abbafati C, Abbas $\mathrm{KM}, \ldots$ \& Duncan $\mathrm{S}$. Global, regional, and national comparative risk assessment of 84 behavioural, environmental and occupational, and metabolic risks or clusters of risks, 1990-2016: a systematic analysis for the Global Burden of Disease Study 2016. Lancet. 2017;390:1345-422.

4. The Korean Society of Hypertension. Guidelines for Hypertension Care; 2019

5. Carey RM, Muntner P, Bosworth HB, Whelton PK. Prevention and control of hypertension: JACC health promotion series. J Am Coll Cardiol. 2018;72:1278-93.

6. Lee SH, Kim YS, Sung SW, Huh BY. A retrospective cohort study on obesity and hypertension risk among Korean adults. J Korean Med Sci. 2005:20:188-95.
7. Lydakis C, Lip GYH, Beevers M, Beevers DG. Diet, lifestyle, and blood pressure. Coronary Health Care. 1997;1:130-7.

8. Gelber RP, Gaziano JM, Manson JE, Buring JE, Sesso HD. A prospective study of body mass index and the risk of developing hypertension in men. Am J Hypertension. 2007;20:370-7.

9. Lee HS, Kwun IS, Kwon CS. Prevalence of hypertension and related risk factors of the older residents in Andong rural area. $J$ Korean Soc Food Sci Nutr. 2009;38:852-61.

10. Nair KS. Age-related changes in muscle. Mayo Clin Proc. 2000; 75:S14-8.

11. Ishii S, Tanaka T, Akishita M, Ouchi Y, Tuji T, lijima K. Metabolic syndrome, sarcopenia and role of sex and age: cross-sectional analysis of Kashiwa cohort study. PLoS One. 2014;9:e112718.

12. Yi D, Khang AR, Lee HW, Son SM, Kang YH. Relative handgrip strength as a marker of metabolic syndrome: the korea national health and nutrition examination survey (KNHANES) VI (2014-2015). Diabetes metab syndr obes: targets and therapy. 2018;11:227-40.

13. Srikanthan P, Karlamangla AS. Relative muscle mass is inversely associated with insulin resistance and prediabetes. findings from the Third national health and nutrition examination survey. J Clin Endocrinol Metab. 2011;96:2898-903.

14. Guillet $C$, Boirie $Y$. Insulin resistance: a contributing factor to age-related muscle mass loss? Diabetes Metab. 2005;31:5S20-6.

15. Anderson JR. Atlas of skeletal muscle pathology. Spiringer; 2011.

16. Chang MJ, Yang SW, Choi HM, Han S. Prevalence among body mass index, lean body mass, and blood pressure in prehypertensive elderly male. Korean J Grow Develop. 2017;25:245-50.

17. Lee JA. Relationship between grip strength and prevalence of hypertension in Korean adults: the sixth Korea national health and nutrition examination survey (2015). Health \& Sports medicine. 2017:19:53-60.

18. Baek SH, Kim EJ, Shin JE. Analysis of the relationship between chronic diseases and grip strength of the Korean senior citizens: focusing on hypertension and diabetes. J Korean Data Analy Soc. 2019;21:2645-56.

19. Lawman HG, Troiano RP, Perna FM, Wang CY, Fryar CD, Ogden $\mathrm{CL}$. Associations of relative handgrip strength and cardiovascular disease biomarkers in U.S. adults, 2011-2012. Am J Prev Med. 2016:50:677-83.

20. Choquette S, Bouchard DR, Doyon CY, Sénéchal M, BrochuM, Dionne IJ. Relative strength as a determinant of mobility inelders 67-84 years of age. a nuage study: nutrition as a determinant of successful aging. J Nutr Health Aging. 2010;14:190-5.

21. Choi EY. The association of relative handgrip strength with type 2 diabetes among Koreans aged 20 years or more. Korean $J$ Health Promot. 2019;19:77-83.

22. Hong SH, Byeon JY, Min JH, Park DH, JWH, Jeon JY. Relationship between handgrip strength and the prevalence of diabetes mellitus among Korean adults: Korean national health and nutrition examination survey, 2014-2018. Exercise Science. 2021;30;11021.

23. Korea Sports Promotion Foundation. Introduction to Korean National Fitness Assessment 100; 2020.

24. Jo JH. Developing regression model for estimation of $\%$ body fat from body mass index. Korean J Phys Educ. 2006;45:869-78.

25. Jung SM, Cho WJ. The effect of body composition and functional fitness on prevalence of hypertension according to gender and the 
elderly. Korean J Sport Sci. 2018;27:1275-87.

26. Kim HR, Son HK. Prevalence of hypertension and its risk factors among aged 65 and over in Korea. J Korean Biol Nurs Sci. 2012;14:282-90.

27. Bentley DC, Nguyen CH, Thomas SG. Resting blood pressure reductions following isometric hand grip exercise training and the impact of age and sex: protocol for a systematic review. Syst Rev. 2015;4:176-80.

28. Statistics Korea. Statistics for the elderly; 2020. 